Sharif University of Technology
Scientia Iranica
SCIENTIA

\title{
Effect of convective transport mechanisms on heat transfer characteristics of nanofluids
}

\author{
E. Mohammadpour ${ }^{\mathrm{a}, *}$ and M. Eghdamtalab ${ }^{\mathrm{b}}$ \\ a. Department of Mechanical Engineering, K.N. Toosi University of Technology, Tehran, Iran. \\ b. Faculty of Chemical Engineering, Malek Ashtar University of Technology, Tehran, Iran.
}

Received 7 September 2014; received in revised form 27 July 2015; accepted 27 October 2015

\author{
KEYWORDS \\ Nanofluids; \\ Convective heat \\ transfer; \\ Two phase approach; \\ Laminar flow.
}

\begin{abstract}
In this study, effect of different slip mechanisms that can produce a slip velocity between nanoparticles and base fluid in a nanofluid flow field has been investigated numerically. A two-phase Euler-Lagrange approach was applied to simulate heat transfer characteristics of different nanoparticles in a straight tube under laminar flow condition. Effect of different mechanisms such as thermophoresis, Brownian diffusion, and Saffman lift force on convective heat transfer was investigated and discussed. It is noticed that only Brownian diffusion and thermophoresis are important slip mechanisms in nanofluids. In different nanofluids, effect of Brownian diffusion and thermophoresis on convective heat transfer is different. While effect of Brownian diffusion is more important in $\mathrm{CuO}$-water nanofluid, thermophoresis is the main slip mechanism in $\mathrm{Al}_{2} \mathrm{O}_{3}$-water nanofluid.
\end{abstract}

(C) 2016 Sharif University of Technology. All rights reserved.

\section{Introduction}

Two decades ago, Masuda et al. [1] observed that thermal conductivity enhances by dispersing submicron particles in base fluid. In comparison with coolant fluids, most solids, especially metals, show much higher thermal conductivity. Therefore, fluids with suspended solid particles are expected to have higher heat transfer properties compared to conventional heat transfer fluids. Experimental applications of these fluids with suspended particles of millimeter or micrometer size show some difficulties, such as instability, erosion and flow channel clogging, and extra penalty of pressure drop in the flow channel [2-5]. The term nanofluid was first proposed by Choi [6] to indicate engineered colloids composed of nanoparticles dispersed uniformly and stably in a base fluid. Several authors have investigated several nanoparticles with different volume fractions and sizes in various base fluids [7-9]. Their

*. Corresponding author. Fax: +982188674748 E-mail address: mohammadpour@sina.kntu.ac.ir (E. Mohammadpour) results have uncovered higher thermal conductivity of nanofluids compared to that of base fluids. Eastman et al. [10] applied copper particles with $10 \mathrm{~nm}$ diameter and observed that thermal conductivity enhancement is about $40 \%$ at $3 \%$ volume fraction. However, some disagreements exist in the literature in terms of mechanisms of heat transfer enhancement under various conditions. Different parameters such as particle type, volume fraction, and particle diameter can affect the amount of enhancement in convective heat transfer. Akbaridoost et al. [11] studied the numerically and experimentally laminar steady-state flow in helically coiled tubes at a constant wall temperature. Their results revealed that utilizing nanofluids enhances heat transfer, and more enhanced heat transfer is observed for tubes with greater curvature ratio. It has been demonstrated that the effect of particle volume fraction is more significant for turbulent flow regime than laminar flow regime [12]. It is also observed that the rate of heat transfer enhancement is different in different duct shapes [13]. Bianco et al. [14] investigated turbulent forced convection flow of water- $\mathrm{Al}_{2} \mathrm{O}_{3}$ nanofluid in a circular tube subjected to a constant and 
uniform heat flux at the wall. Their results showed that heat transfer enhancement increases with the particle volume concentration and Reynolds number. Two general approaches are applied for modeling the nanofluid flow field and heat transfer characteristics: single-phase and two-phase approaches. In singlephase approach, the base fluid and nanoparticles are considered to be in thermal equilibrium, and the effect of nanoparticles are just considered in effective properties. But, according to Brownian motion of ultrafine particles, different mechanisms can produce the slip velocity between nanoparticles and base fluid. Therefore, the nanoparticles can be considered as a discrete phase, and the Lagrangian approach is applied for modeling the nanofluid flow field and heat transfer characteristics. Peng et al. [15] made comparisons between the single-phase model, EulerEuler two-phase model, and Euler-Lagrange two-phase model. They noticed that the Euler-Lagrange model produces more accurate results compared to the other two approaches.

In this paper, Effect of different mechanisms of particle diffusions such as thermophoresis, Brownian, and lift on convective heat transfer of different nanofluid in a circular tube is investigated and discussed. Two-phase Euler-Lagrange approach is applied to study the laminar forced convection flow of different nanofluids in a uniformly heated tube. The convective heat transfer of two-phase Euler-Lagrange model and homogenous single-phase model is compared with the experimental data.

\section{Mathematical model}

In the single-phase approach, both the fluid and the nanoparticles are considered as a homogenous singlephase fluid. The conservative equations of continuity, momentum, and energy for pure fluid are extended to nanofluids using effective properties of the nanofluids. These effective properties are obtained from experimental or theoretical data. On the other hand, in the two-phase approach, the fluid phase is considered continuous and nanoparticles are dispersed through it. Consequently, effects of nanoparticles and base fluid interactions are entered as a source term in momentum and energy equations.

\subsection{Single-phase approach}

In single-phase method, the conservation equations are written in the same form of the base fluid, but thermo physical properties will be replaced with appropriate properties of the nanofluids like below:

- Continuity equation:

$$
\nabla \cdot\left(\rho_{n f} \mathbf{v}\right)=0
$$

- Momentum equation:

$$
\nabla \cdot\left(\rho_{n f} \mathbf{v v}\right)=-\nabla p+\nabla \cdot\left(\mu_{n f} \nabla \mathbf{v}\right) .
$$

- Energy equation:

$$
\nabla \cdot\left(\rho_{n f} \mathbf{c}_{p, n f} \mathbf{v} T\right)=\nabla \cdot\left(k_{n f} \nabla T\right) .
$$

2.1.1. Thermo physical properties of nanofluids In this study, the following correlations have been applied to compute properties of the $\mathrm{Al}_{2} \mathrm{O}_{3}$-water and $\mathrm{CuO}$-water nanofluids:

$$
\begin{aligned}
& \rho_{n f}=\phi \rho_{p}+(1-\phi) \rho_{f}, \\
& c_{p, n f}=\phi c_{p, p}+(1-\phi) c_{p, f} .
\end{aligned}
$$

Correlation of $\mathrm{Yu}$ and Choi [16] has been used to calculate thermal conductivity of the $\mathrm{Al}_{2} \mathrm{O}_{3}$-water and $\mathrm{CuO}$-water nanofluids. This correlation only considers the effect of nanoparticle volume fraction on thermal conductivity:

$$
k_{n f}=k_{f}\left[\frac{k_{p}+2 k_{f}+2\left(k_{p}-k_{f}\right)(1+\beta)^{3} \phi}{k_{p}+2 k_{f}-\left(k_{p}-k_{f}\right)(1+\beta)^{3} \phi}\right],
$$

where $\beta$ is the nanolayer thickness to radius of nanoparticle; $\beta=0.1$ has been considered in order to compute effective thermal conductivity of the $\mathrm{Al}_{2} \mathrm{O}_{3}$-water and $\mathrm{CuO}$-water nanofluids [17].

In order to consider the effect of temperature variation on heat transfer conductivity of nanofluid, Chon correlation [18] was used for calculating the effective thermal conductivity.

$$
\begin{aligned}
\frac{k_{\text {eff }}}{k_{f}}= & +64.7 \times \phi^{0.7460}\left(\frac{d_{f}}{d_{p}}\right)^{0.3690}\left(\frac{k_{s}}{k_{f}}\right)^{0.7476} \\
& \times \operatorname{Pr}^{0.9955} \times \operatorname{Re}^{1.2321}
\end{aligned}
$$

where $\operatorname{Pr}$ and Re in Eq. (7) are defined as:

$$
\begin{aligned}
& \operatorname{Pr}=\frac{\mu}{\rho_{f} \alpha_{f}}, \\
& \operatorname{Re}=\frac{\rho_{f} B_{c} T}{3 \pi \mu^{2} l_{B F}} .
\end{aligned}
$$

$l_{B F}$ is the mean free path of water and the calculated value of $0.17 \mathrm{~nm}$ is used for water in modeling, $B_{c}$ is Boltzmann constant; and $\mu$ is calculated by the following equation:

$$
\begin{aligned}
& \mu=A \times 10^{\frac{B}{T-C}}, \quad C=140, \quad B=247, \\
& A=2.414 e-5 .
\end{aligned}
$$

Effective viscosity of $\mathrm{CuO}$-water nanofluid can be calculated by Birkman's model [19] as follows:

$$
\mu_{n f}=\frac{\mu_{f}}{(1-\phi)^{2.5}} .
$$

Maiga [20] equation is used to calculate the viscosity of $\mathrm{Al}_{2} \mathrm{O}_{3}$-water nanofluid:

$$
\mu_{n f}=\left(123 \phi^{2}+7.3 \phi+1\right) \mu_{f} \text {. }
$$




\subsection{Two-phase approach}

The Euler-Lagrange two-phase approach is applied to obtain the effect of nanoparticles slip velocity on base fluid flow and heat transfer characteristics. The influence of nanoparticles in base fluid is considered as a source term in momentum and energy equations. Therefore, the conservative equations are presented as below:

- Continuity equation:

$$
\nabla \cdot \mathbf{v}_{f}=0 .
$$

- Momentum equation:

$$
\nabla \cdot\left(\mathbf{v}_{f} \mathbf{v}_{f}\right)=-\frac{1}{\rho_{f}} \nabla p+\nabla \cdot\left(v_{f} \nabla \mathbf{v}_{f}\right)+\frac{\mathbf{S}_{m}}{\rho_{f}}
$$

where $\mathbf{S}_{m}$ in Eq. (13) is the momentum transfer between base fluid and nanoparticles and can be obtained from the instant variation of nanoparticles momentum when they pass from the control volume:

$$
\mathbf{S}_{m}=\sum m_{p} \mathbf{F} \Delta t
$$

where $\mathbf{F}$ is the force per unit particle mass and $m_{p}$ is particle mass. This force is equal to the rate of momentum within the control volume:

$$
\mathbf{F}=\frac{d v_{p}}{d t}
$$

where, $\mathbf{v}_{p}$ is the nanoparticle velocity. Different forces that cause slip velocity between nanoparticles and base fluid are considered as below:

$$
\mathbf{F}=\mathbf{F}_{G}+\mathbf{F}_{L}+\mathbf{F}_{V}+\mathbf{F}_{D}+\mathbf{F}_{T}+\mathbf{F}_{B}
$$

where $\mathbf{F}_{G}$ is the gravity force and can be calculated by:

$$
\mathbf{F}_{G}=\frac{\left(\rho_{p}-\rho_{f}\right) \mathbf{g}}{\rho_{p}},
$$

and $\mathbf{F}_{L}$ is the Saffman lift force and can be obtained by [21]:

$$
\mathbf{F}_{L}=\frac{2 K \nu^{1 / 2} \rho_{f} d_{i j}}{\rho_{p} d_{p}\left(d_{i j} d_{i j}\right)^{1 / 4}}\left(\mathbf{v}_{f}-\mathbf{v}_{p}\right),
$$

where $K=2.594$ and $d_{i j}$ is deformation tensor.

Virtual mass force arises due to acceleration from relative velocity [22] and can be obtained by:

$$
\mathbf{F}_{V}=\frac{\rho_{f}}{2 \rho_{p}}\left(\dot{\mathbf{v}}_{f}-\dot{\mathbf{v}}_{p}\right) .
$$

For sub-micron particles due to the small relative Reynolds number, the drag force is the computed form of Stokes' drag law [23]:

$$
\mathbf{F}_{D}=\frac{18 \mu_{f}}{d_{p}^{2} \rho_{p} C_{c}}\left(\mathbf{v}_{f}-\mathbf{v}_{p}\right)
$$

where $C_{c}$ is Cunningham correction factor to Stokes' drag law and can be calculated from:

$$
C_{c}=1+\frac{2 \lambda}{d_{p}}\left(1.257+0.4 e^{-\left(1.1 d_{p} / 2 \lambda\right)}\right)
$$

where $\lambda$ is the molecular mean free path.

Thermophoresis is the motion of particles in a fluid, which is subject to a steady temperature gradient. At sufficiently long times, the stronger molecular impulses in the hotter fluid region drive nanoparticles towards the colder region, where the molecular impulses are weaker. The following formula which was introduced by Epstin [24] is used for the thermophoretic force.

$$
\mathbf{F}_{T}=-9 \pi \mu_{f}^{2} d_{p} \frac{k_{f}}{2 k_{f}+k_{p}} \frac{\nabla T}{\rho_{f} m_{p} T} .
$$

Nanoparticles are the same order of fluid molecules and the collision between nanoparticles; fluid molecules can cause random motion and slip velocity. This random motion of nanoparticles are called Brownian, and the Brownian force $\left(\mathbf{F}_{B}\right)$ is modeled as a Gaussian function with spectral intensity of $S_{n, i j}$ [25]:

$$
\begin{aligned}
& S_{n, i j}=S_{0} \delta_{i j}, \\
& S_{0}=\frac{216 \nu k_{B} T}{\pi^{2} \rho_{f} d_{p}^{5}\left(\frac{\rho_{p}}{\rho_{f}}\right)^{2} C_{c}},
\end{aligned}
$$

where $\delta_{i j}$ is the Kronecker delta function, $T$ is the fluid temperature, $\nu$ is the kinematic viscosity, and $k_{B}$ is the Boltzmann constant. Energy equation is obtained as follows:

$$
\nabla \cdot\left(\mathbf{v}_{f} T_{f}\right)=\nabla \cdot\left(\alpha_{f} \nabla T_{f}\right)+\frac{S_{e}}{\rho_{f} c_{p, f}},
$$

where $S_{e}$ in Eq. (26) is the source term related to energy transferred between nanoparticle and base fluid:

$$
S_{e}=\sum \dot{Q} \Delta t
$$

where $\dot{Q}$ is the total convective heat transfer from the particle and is obtained by:

$$
\dot{Q}=\mathrm{Nu} \pi d_{p} k_{f}\left(T_{p}-T_{f}\right),
$$

where $\mathrm{Nu}$ is computed using the Ranz and Marshall correlation [26]:

$$
\mathrm{Nu}=2.0+0.6 \operatorname{Re}_{d}^{1 / 2} \operatorname{Pr}^{1 / 3}
$$




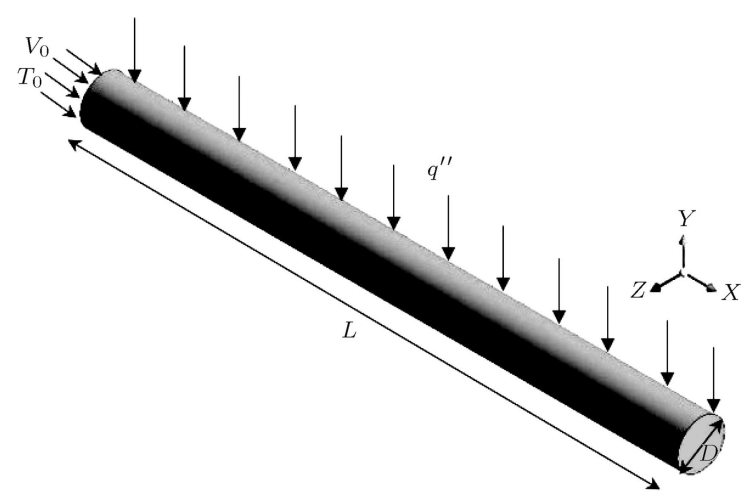

Figure 1. Geometry and boundary condition of considered problem.

Table 1. Considered boundary condititions.

\begin{tabular}{cc}
\hline Boundary index & Value \\
\hline$L$ & $1 \mathrm{~m}$ \\
$D$ & $8 \mathrm{~mm}$ \\
$V_{0}$ & $0.17 \mathrm{~m} / \mathrm{s}$ \\
$T_{0}$ & $300 \mathrm{~K}$ \\
$d_{p}$ & $40 \mathrm{~nm}$ \\
$q^{\prime \prime}$ & $9000 \mathrm{~W} / \mathrm{m}^{2}$ \\
\hline
\end{tabular}

\section{Geometry and boundary conditions}

The geometry of considered problem is shown in Figure 1. It consists of $8 \mathrm{~mm}$ diameter tube with $1 \mathrm{~m}$ length. For water (continuous phase), a uniform distribution of velocity $\left(V_{0}\right)$ and temperature $\left(T_{0}\right)$ is assumed at tube inlet. At the tube outlet, the fully developed condition is assumed, which states that all axial derivatives are zero. For $\mathrm{CuO}$ and $\mathrm{Al}_{2} \mathrm{O}_{3}$ nanoparticles (dispersed phase), the constant amount of velocity and temperature is prevailed at tube inlet. It is also assumed that all particles have the same diameter $\left(d_{p}\right)$. A constant heat flux condition $\left(q^{\prime \prime}\right)$ is assumed at the tube wall. A no-slip condition is employed at wall for the continuous phase and the reflect condition for the dispersed phase. Table 1 shows the considered boundary conditions.

\section{Numerical method and validation}

The dimensioned governing equations, i.e., Eqs. (1) to (3), (12), (13), and (25), are discretized using a control volume method. The second order upwind and power low schemes are, respectively, used to approximate convection and diffusion terms in the differential equations, while SIMPLE procedure has been applied for the velocity-pressure coupling. The solution domain is discretized with a non-uniform spacing mesh in the radial direction with grids clustering toward the walls, which allows the boundary layers to be resolved without an excessive number of grids. The coupling be-

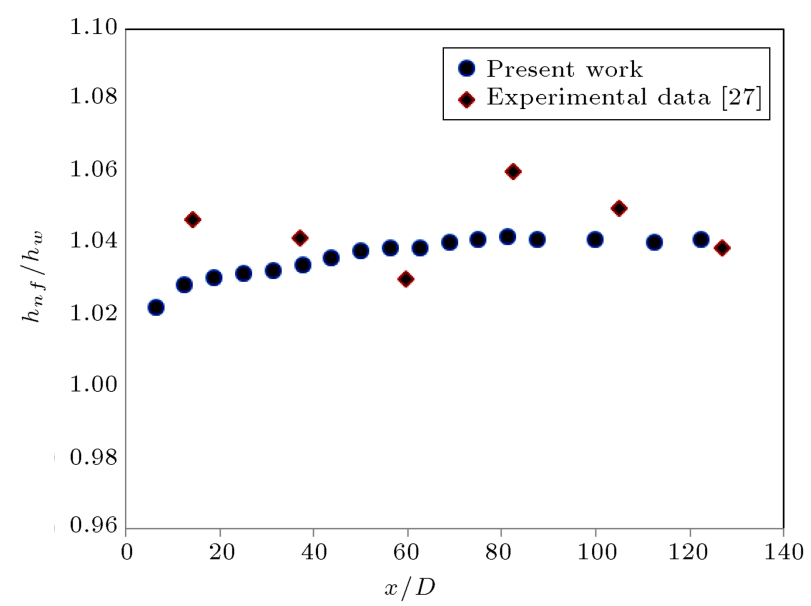

Figure 2. Comparison between the predicted convective heat transfer and the experimental data at $\phi=0.3 \%$ and $\operatorname{Re}=1350$.

tween fluid and nanoparticles is two-way, and discrete phase elements are updated in every flow iteration. In order to ensure the accuracy as well as the consistency of numerical results, several non-uniform grids were subjected to an extensive testing procedure for each of the cases considered. Results obtained for a particular test case showed that for the tube flow problem under consideration, the $1200 \times 25$ non-uniform grid appears to be satisfactory to ensure the precision of numerical results as well as their independency with respect to the number of nodes used. The selected grid for the current calculations consists of 1200 and 25 nodes in the axial and radial directions, respectively.

In order to evaluate validity and precision of the numerical model, comparison with the existing experimental data has been employed. Figure 2 illustrates a comparison between the calculated results of $\mathrm{CuO}$-water nanofluid and the experimental data of Asirwatham et al. [27] in a tube at $\phi=0.3 \%$ and $\operatorname{Re}=1350$. It can be observed that the numerical simulation results are in good agreement with the experimental data, and the average error is less than $2 \%$. Therefore, the numerical procedure is reliable and can predict forced convection in a horizontal tube.

\section{Results and discussion}

Results have been obtained by employing the singlephase and two-phase models for different Reynolds number and volume fractions. In all cases, the size of the spherical particles is considered equal to $40 \mathrm{~nm}$. The initial simulations are performed on single-phase model for both constant and temperature-dependent properties, and two-phase Euler-Lagrange method to check the reliability and accuracy of each numerical method. The results are compared with the experimental data of Asirvatham et al. [27] at $\phi=0.3 \%$ and $\operatorname{Re}=$ 1350 in Figure 3. It can be observed that the single- 


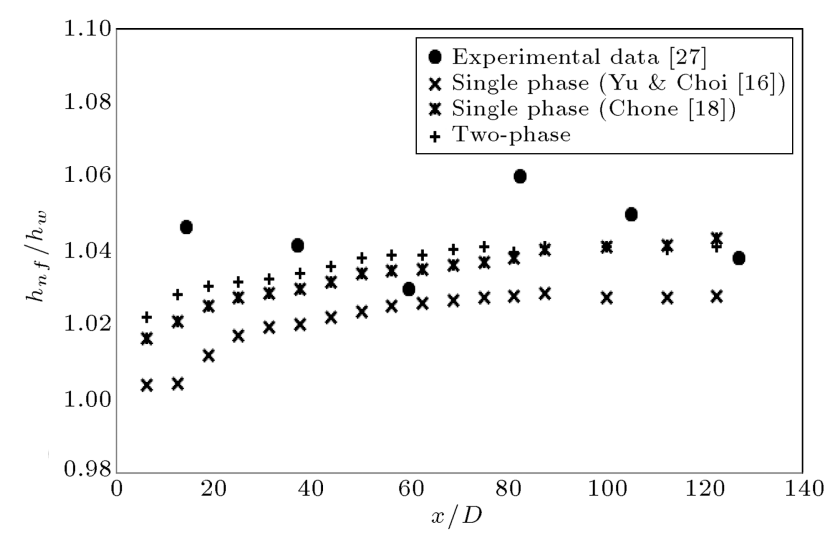

Figure 3. Comparison of two different single-phases and two-phase models with experimental data [27] at $\phi=0.3 \%$ and $\operatorname{Re}=1350$.

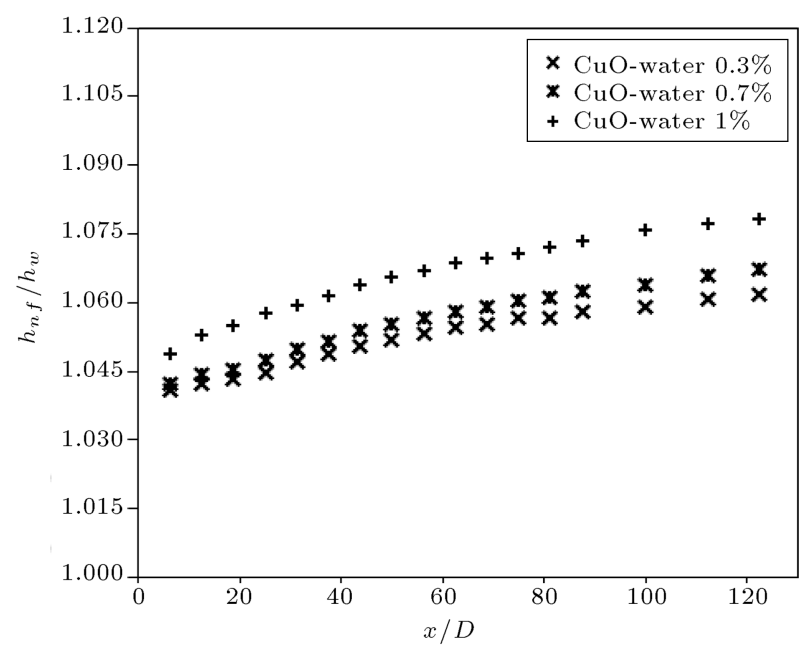

Figure 4. Effect of particle volume fraction on convective heat transfer of $\mathrm{CuO}$-water nanofluid at $\mathrm{Re}=100$.

phase model based on constant properties (Yu and Choi model [16]) does not predict convective heat transfer of the nanofluid through the tube length in contrast with the two-phase Euler-Lagrange approach. While the average discrepancy of the two-phase model with the experimental data is less than $2 \%$, this discrepancy for single-phase [16] is $8 \%$. However, the single-phase model that considers the effect of random motion of nanoparticles [18] shows the better results and its average discrepancy is $3.6 \%$.

Figures 4 and 5 exhibit the effect of nanoparticle volume fraction on convective heat transfer of $\mathrm{CuO}$ water and $\mathrm{Al}_{2} \mathrm{O}_{3}$-water nanofluids at $\mathrm{Re}=100$. It is observed that the amount of enhancement in heat transfer coefficient increases with concentration of the nanoparticles. While the amount of enhancement increases along the tube for $\mathrm{CuO}$-water nanofluid, this amount is almost constant for $\mathrm{Al}_{2} \mathrm{O}_{3}$-water nanofluid. The main reason is concerned with the higher thermal conductivity of $\mathrm{CuO}$ nanoparticles than $\mathrm{Al}_{2} \mathrm{O}_{3}$ nanoparticles. Through flow direction, fluid temper-

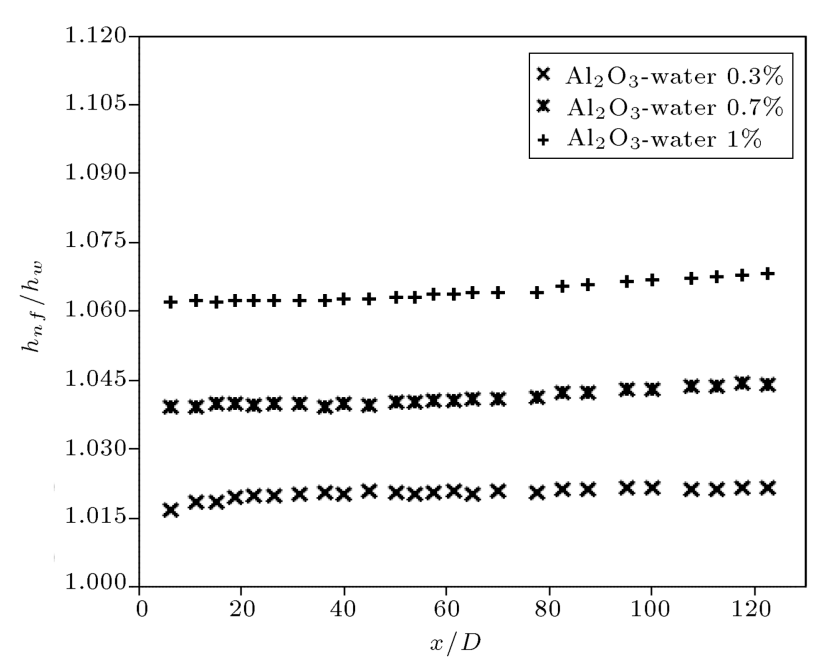

Figure 5. Effect of particle volume fraction on convective heat transfer of $\mathrm{Al}_{2} \mathrm{O}_{3}$-water nanofluid at $\mathrm{Re}=100$.

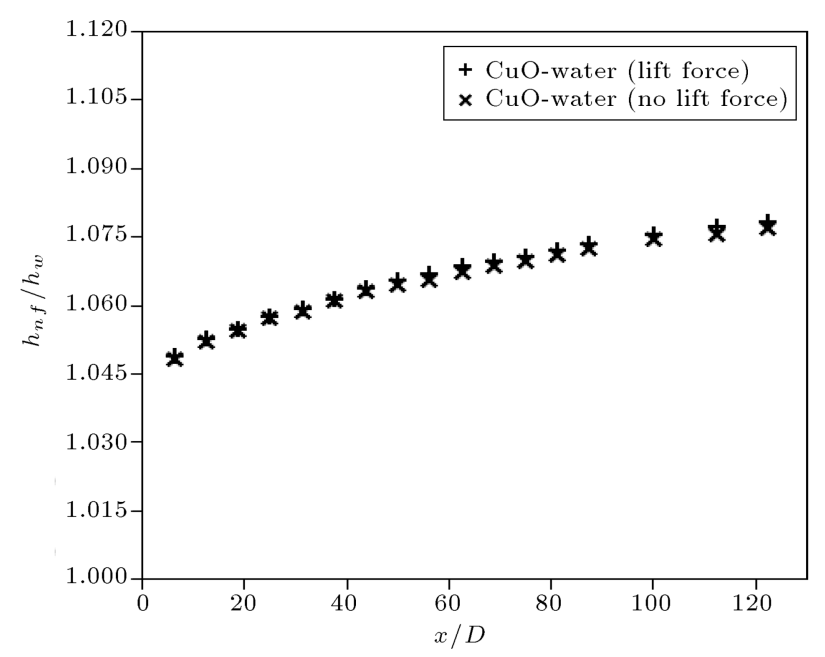

Figure 6. Effect of Saffman lift force on convective heat transfer of $\mathrm{CuO}$-water nanofluid at $\mathrm{Re}=100$ and $\phi=1 \%$.

ature increases and $\mathrm{CuO}$ nanoparticles accelerate the heat transfer between fluid layers.

The effect of different particle transport mechanisms on convective heat transfer of $\mathrm{CuO}$-water nanofluid is studied in Figures 6-8. The evaluation is done at $\operatorname{Re}=100$ and volume concentration of $1 \%$. They illustrate the effect of Saffman lift force, thermophoretic force, and Brownian force on convective heat transfer coefficient, respectively.

It is observed that the effect of Saffman lift force on convective heat transfer against thermophoretic and Brownian forces is negligible. For $\mathrm{CuO}$-water nanofluid, Brownian effects on convective heat transfer are more important than thermophoresis effects. While elimination of the thermophoretic force from simulation has affected the amount of this enhancement and caused some $0.25 \%$ relative decrease in the convective heat transfer, eliminating Brownian force from model incurred $0.35 \%$ relative decrease in the convective heat 


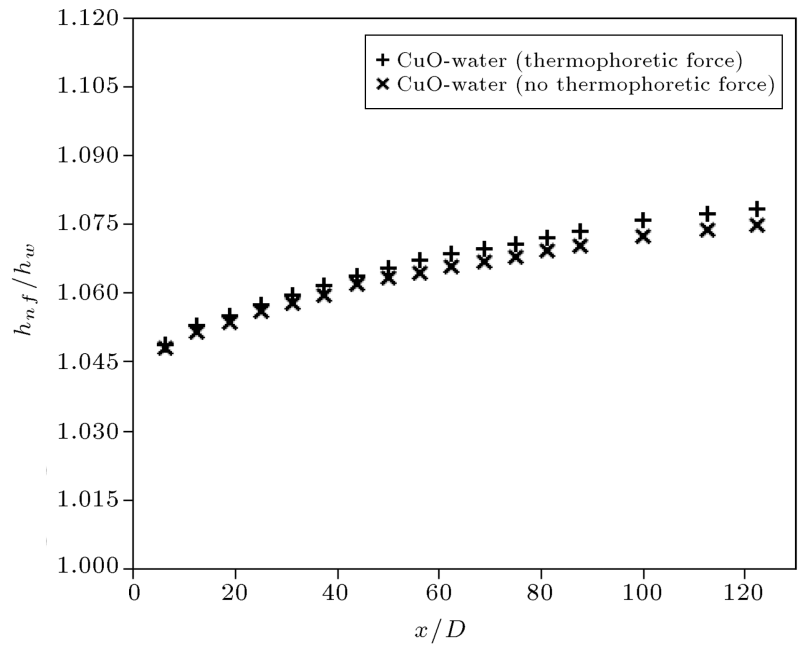

Figure 7. Effect of thermophoretic force on convective heat transfer of $\mathrm{CuO}$-water nanofluid at $\mathrm{Re}=100$ and $\phi=1 \%$.

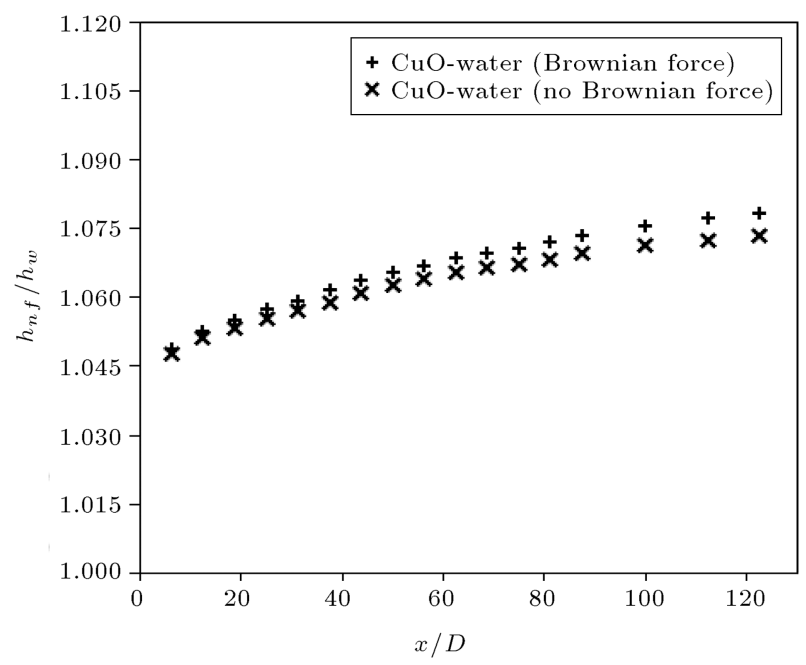

Figure 8. Effect of Brownian force on convective heat transfer of $\mathrm{CuO}$-water nanofluid at $\mathrm{Re}=100$ and $\phi=1 \%$.

transfer. Similar to the thermophoretic force, the role of Brownian force becomes more significant along the tube length. It is observed that the effect of thermophoretic and Brownian force on the rate of heat transfer enhancement is more prominent at greater volume fractions.

Figures 9-11 show the effect of particle transport mechanisms on convective heat transfer of $\mathrm{Al}_{2} \mathrm{O}_{3}$-water nanofluid. The evaluation is performed at $\operatorname{Re}=100$ and volume concentration of $1 \%$. The effect of Saffman lift force, thermophoretic force, and Brownian force on convective heat transfer coefficient of $\mathrm{Al}_{2} \mathrm{O}_{3}$ is investigated.

Similar to CuO-water nanofluid, the effect of Saffman lift force on convective heat transfer against thermophoretic and Brownian forces is negligible. For $\mathrm{Al}_{2} \mathrm{O}_{3}$-water nanofluid, thermophoresis effects on convective heat transfer are of the same order or more

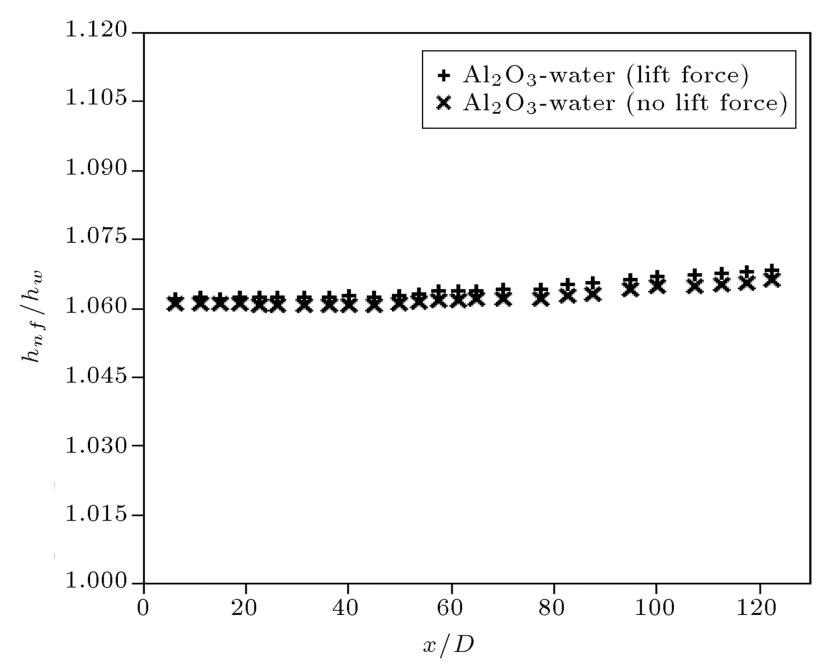

Figure 9. Effect of Saffman lift force on convective heat transfer of $\mathrm{Al}_{2} \mathrm{O}_{3}$-water nanofluid at $\mathrm{Re}=100$ and $\phi=1 \%$.

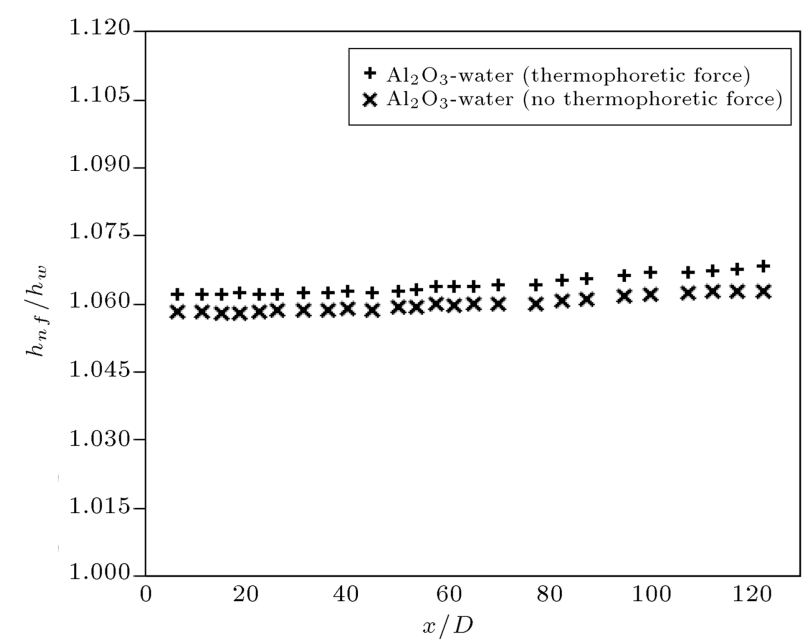

Figure 10. Effect of thermophoretic force on convectiveheat transfer of $\mathrm{Al}_{2} \mathrm{O}_{3}$-water nanofluid at $\mathrm{Re}=$ 100 and $\phi=1 \%$.

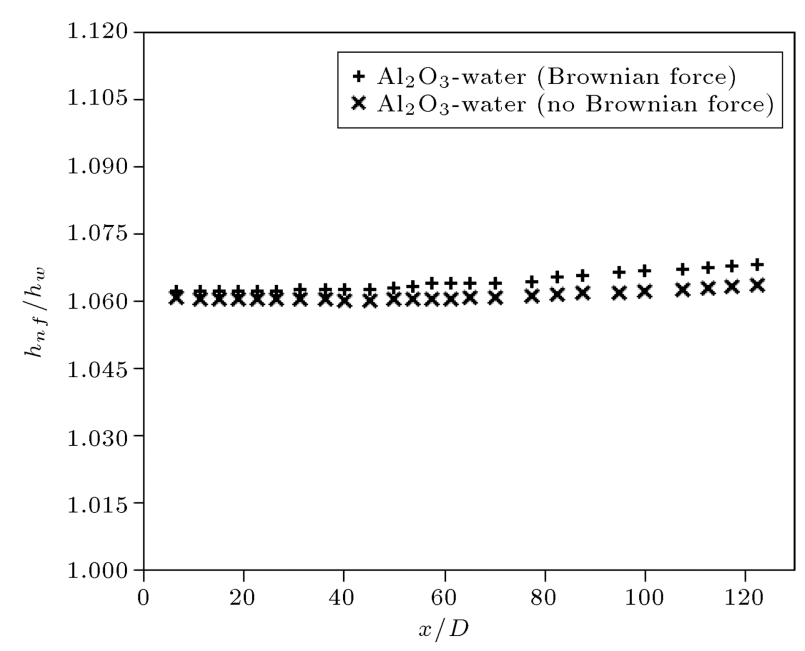

Figure 11. Effect of Brownian force on convective heat transfer of $\mathrm{Al}_{2} \mathrm{O}_{3}$-water nanofluid at $\mathrm{Re}=100$ and $\phi=1 \%$. 
important than Brownian effects. While elimination of the thermophoretic force from simulation has affected the amount of this enhancement and caused $0.45 \%$ relative decrease in average in the convective heat transfer, eliminating Brownian force from model incurred $0.35 \%$ relative decrease in the convective heat transfer. According to higher thermal conductivity of $\mathrm{CuO}$ nanoparticles which makes lower thermal diffusion, thermophoresis effects in $\mathrm{Al}_{2} \mathrm{O}_{3}$-water nanofluid are more important than $\mathrm{CuO}$-water nanofluid. Moreover, according to higher density of $\mathrm{CuO}$ nanoparticles, collisions between particles and fluid molecules become more important, and effect of Brownian motion on convective heat transfer is more considerable.

\section{Conclusions}

A two-phase Euler-Lagrange approach has been applied to investigate the effect of transform mechanisms on heat transfer characteristics of nanofluids in a straight tube. A comparison between two-phase EulerLagrange and homogenous single-phase model has been implemented to predict heat transfer characteristics of nanofluids. It was observed that the two-phase EulerLagrange model is more precise than the homogenous model. Slip mechanisms between particles and base fluid were not predicted by single phase model. Different mechanisms have been considered that can produce slip velocity between nanoparticles and base fluid. It has been observed that only Brownian diffusion and thermophoresis are important slip mechanisms in nanofluids. In different nanofluids, effect of each one on convective heat transfer is different. While in $\mathrm{CuO}$ water nanofluid effect of Brownian diffusion is more important, thermophoresis is the main slip mechanism in $\mathrm{Al}_{2} \mathrm{O}_{3}$-water nanofluid.

\section{Nomenclature}

$\begin{array}{ll}c_{p} & \text { Specific heat } \\ C_{c} & \text { Cunningham correction factor to } \\ & \text { Stokes' drag law } \\ D & \text { Tube diameter } \\ d_{p} & \text { Particle diameter } \\ d_{i j} & \text { Deformation tensor } \\ \mathbf{F} & \text { Total force applied to particle } \\ \mathbf{F}_{B} & \text { Brownian force } \\ \mathbf{F}_{D} & \text { Drag force } \\ \mathbf{F}_{G} & \text { Gravity force } \\ \mathbf{F}_{L} & \text { Lift force } \\ \mathbf{F}_{T} & \text { Thermophoretic force } \\ \mathbf{F}_{V} & \text { Virtual mass force } \\ \mathbf{g} & \text { Gravity acceleration }\end{array}$

$\begin{array}{ll}h & \text { Convective heat transfer coefficient } \\ k & \text { Thermal conductivity } \\ k_{B} & \text { Boltzmann constant } \\ \mathrm{Kn} & \text { Knudsen number } \\ k_{s} & \text { Coefficient } \\ m & \text { Mass } \\ \mathrm{Nu} & \text { Nusselt number } \\ p & \text { Pressure } \\ \mathrm{Pr} & \text { Prandtl number } \\ Q & \text { Total heat flux } \\ S_{p} & \text { Source term } \\ t & \text { Time } \\ T & \text { Temperature } \\ X & \text { Axial distance } \\ \mathbf{v} & \text { Velocity }\end{array}$

\section{Greek Symbols}

$\beta \quad$ Ratio of the nanolayer thickness to the original particle radius

$\rho \quad$ Density

$\lambda \quad$ Mean free path of the fluid

$\phi \quad$ Particle volume fraction

$\delta_{i j} \quad$ Kronecker delta function

$\zeta_{i} \quad$ Zero-mean, unit-variance-independent Gaussian random number

$\mu \quad$ Dynamic viscosity

$\nu \quad$ Kinematic viscosity

\section{Subscripts}

$\begin{array}{ll}n f & \text { Nanofluid } \\ f & \text { Fluid } \\ p & \text { Particle } \\ m & \text { Mean }\end{array}$

\section{References}

1. Masuda, H., Ebata, A., Teramae, K. and Hishinuma, N. "Alteration of thermal conductivity and viscosity of liquid by dispersing ultra-fine particles", Netsu Bussei, 4(4), pp. 227-233 (1993).

2. Keblinski, P., Phillpot, S.R., Choi, S.U.S. and Eastman, J.A. "Mechanism of heat flow in suspension of nano-sized particle (nanofluids)", Int. J. Heat Mass Transfer, 45, pp. 855-863 (2002).

3. Xie, H., Wang, J., Xi, T. and Liu, Y. "Thermal conductivity of suspensions containing SiC particles", Int. J. Thermophysics, 23, pp. 571-580 (2002).

4. Wang, B.X., Zhou, L.P. and Peng, X.F. " A Fractal model for predicting the effective thermal conductivity of fluid with suspension of nanoparticles", Int. J. Heat Mass Transfer, 46, pp. 2665-2672 (2003). 
5. Siddique, M., Khaled, A.R.A., Abdulhafiz, N.I. and Boukhary, A.Y. "Recent advances in heat transfer enhancements: A review", Int. J. Chem. Eng., 106461, 28 pages $(2010)$.

6. Choi, S. "Enhancing thermal conductivity of fluids with nanoparticles", Dev. and App. of Non-Newtonian Flows, D.A. Siginer and H.P. Wang, Eds., ASME, 231(66), pp. 99-105 (1995).

7. Kleinstreuer, C. and Feng, Y. "Experimental and theoretical studies of nanofluid thermal conductivity enhancement: a review", 6:229, Nanoscale Res. Lett. (2011).

8. Zabihi, K., Gholamian, F. and Vasefi, S.I. "Experimental and numerical investigation of $\mathrm{Al}_{2} \mathrm{O}_{3}$-Water nanofluid inside a triangular tube", World Appl. Sci. J., 22(5), pp. 601-607 (2013).

9. Karthik, R., Harish Nagarajan, R., Praveen, K.S. and Raja, B. "Experimental investigation on thermal conductivity enhancement of copper (II) oxide-DI water nanofluid", J. Eng. Thermophysics, 23(4), pp. 341-349 (2014).

10. Eastman, J.A., Choi, S.U.S., Li, S., Yu, S. and Thompson, L.J. "Anomalously increased effective thermal conductivities of ethylene glycol-based nanofluids containing copper nanoparticles", App. Phys. Letters, 78(6), pp. 718-720 (2001).

11. Akbaridoust, F., Rakhsha, M., Abbassi, A. and SaffarAvval, M. "Experimental and numerical investigation of nanofluid heat transfer in helically coiled tubes at constant wall temperature using dispersion model", Int. J. Heat Mass Transfer, 58(1-2), pp. 480-491 (2013).

12. He, Y., Jin, Y., Chen, H., Ding, Y., Cang, D. and Lu, H. "Heat transfer and flow behavior of aqueous suspensions of $\mathrm{TiO}_{2}$ nanoparticles (nanofluids) flowing upward through a vertical pipe", Int. J. Heat Mass Transfer, 50, pp. 2272-2281 (2007).

13. Vasefi, I. and Alizadeh, M. "A Numerical investigation of Cuo-water nanofluid in different geometries by twophase euler-lagrange method", World Appl. Sci. J., 26(10), pp. 1323-1329 (2013).

14. Bianco, V., Manca, O. and Nardini, S. "Numerical investigation on nanofluids turbulent convection heat transfer inside a circular tube", Int. J. Therm. Sci., 50(3), pp. 341-349 (2011).

15. Peng, W., Minli, B., Jizu, L., Liang, Z., Wenzheng, C. and Guojie, L. "Comparison of multidimensional simulation models for nanofluids flow characteristics", Numer. Heat Transf. Part B Fundam, 63(1), pp. 62-83 (2013).

16. Yu, W. and Choi, S.U.S. "The role of interfacial layers in the enhanced thermal conductivity of nanofluids: A renovated Maxwell model", J. Nanopart. Research, 5, pp. 167-171 (2003).

17. Fotukian, S.M. and Nasr Esfahany, M. "Experimental study of turbulent convective heat transfer and pressure drop of dilute $\mathrm{CuO} /$ water nanofluid inside a circular tube", Int. Commun. Heat Mass Transfer, 37, pp. 214-219 (2010).
18. Chon, C.H., Kihm, K.D., Lee, S.P. and Choi, S.U.S. "Empirical correlation finding the role of temperature and particle size for nanofluid $(\mathrm{CuO})$ thermal conductivity enhancement", App. Phys. Lett., 87, pp. 1-3 (2005).

19. Brinkman, H.C. "The viscosity of concentrated suspensions and solutions", J. Chem. Phys., 20, pp. 571-581 (1952).

20. Maiga, S.E., Nguyen, C.T., Galanis, N. and Roy, G. "Heat transfer behaviors of nanofluids in a uniformly heated tube", Super Lattices Microstruct., 35, pp. 54355 (2004).

21. Saffman, P.G. "The lift on a small sphere in a slow shear flow", J. Fluid Mechanics, 22, pp. 385-400 (1965).

22. Crowe, C., Sommerfeld, M. and Tsuji, Y., Multiphase Flows with Droplets and Particles, 2nd Edn., pp. 70-102, CRC Press, Taylor \& Fransic Group, U.S. (1997).

23. Ounis, H., Ahmadi, G. and McLaughlin, J.B. "Brownian diffusion of sub micrometer particles in the viscous sub layer", J. Colloid Interface Science, 143(1), pp. 266-277 (1991).

24. Epstein, P. "Zur theorie des radiometers", Z. Phys., 54, pp. 537-563 (1929).

25. Li, A. and Ahmadi, G. "Dispersion and deposition of spherical particles from point sources in a turbulent channel flow", Aerosol Science and Technology, 16, pp. 209-226 (1992).

26. Ranz, W.E., and Marshall, W.R. "Evaporation from drops, Part I", Chemical Engineering Program, 48(3), pp. 141-146 (1952).

27. Asirvatham, G.L., Vishal, N., Gangatharan, S.K. and Lal, D.M. "Experimental study on forced convective heat transfer with low volume fraction of $\mathrm{CuO} /$ Water nanofluid", J. Energies, 2, pp. 97-119 (2009).

\section{Biographies}

Ebrahim Mohammadpour obtained his BS in Mechanical Engineering (fluid mechanics) from Iran University of Science and Technology, in 2008. He received his MSc degree in Mechanical Engineering from K.N. Toosi University of Technology, in 2010. He is the author of more than 7 papers on various subjects in nanofluids, power plants, turbo machinery, and numerical modeling.

Mohammad Eghdamtalab is a researcher of Chemical Engineering in Malek Ashtar University of Technology, where he has been since 2000. His research areas have been focused on energy and advanced material characterization. Since 2008, he has been the Director of the MUT Center for Computational Materials Laboratory. 